\title{
Cesarean section in the second delivery to prevent anal incontinence after asymptomatic obstetrical anal sphincter injury: the EPIC multicenter randomized trial
}

\author{
laurent abramowitz ${ }^{1}$, Laurent Mandelbrot ${ }^{2}$, Agnes Bourgeois-Moine $^{3}$, Arnaud Le Tohic ${ }^{4}$, \\ Celine De Carné Carnavalet ${ }^{3}$, Olivier Poujade ${ }^{5}$, Carine Roy ${ }^{3}$, and Florence Tubach ${ }^{3}$ \\ ${ }^{1} \mathrm{APHP}$ \\ ${ }^{2}$ Hopital Louis-Mourier \\ ${ }^{3} \mathrm{AP}-\mathrm{HP}$ \\ ${ }^{4}$ Centre Hospitalier de Versailles Service de Gynecologie et Obstetrique \\ ${ }^{5}$ Beaujon Hospital, AP-HP
}

May 5, 2020

\begin{abstract}
Objective: To determine whether planned cesarean section (CS) for a second delivery protects anal continence in women with obstetrical anal sphincter lesions. Design: Randomized trial. Setting: 6 maternity units in the Paris area. Sample : Women at high risk of sphincter lesions (first delivery with 3d degree laceration and/or forceps) but no symptomatic anal incontinence. Methods : Endoanal ultrasound was performed in the third trimester of the second pregnancy. Women with sphincter lesions were randomized to planned CS or vaginal delivery (VD). Main outcome measures : Anal continence at 6 months post-partum. Secondary outcomes were urinary continence, sexual morbidity, maternal and neonatal morbidities and worsening of external sphincter lesions. Results : Anal sphincter lesions were detected by ultrasound in 264/434 women enrolled (60.8\%) ; 112 were randomized to planned VD and 110 to planned CS. At 6-8 weeks after delivery, there was no significant difference in anal continence between the 2 groups. At 6 months after delivery, median Vaizey scores of anal continence were 1 [IQR 0-4] in the CS group and 1 [IQR 0-3] in the VD group $(\mathrm{p}=0.34)$. There were no significant differences for urinary continence, sexual functions or for other maternal and neonatal morbidities. Conclusions : In women with asymptomatic obstetrical anal sphincter lesions diagnosed by ultrasound, planning a CS had no significant impact on anal continence 6 months after the second delivery. These results do not support advising systematic CS for this indication.
\end{abstract}

\section{Introduction}

Anal incontinence is a source of distress for patients, with a major impact on sexual health ${ }^{1}$ and quality of life $^{2,3}$. It is a frequent symptom ${ }^{4}$, with a prevalence $14.8 \%$ among women in a population-based study in the United States ${ }^{5}$. Obstetrical anal sphincter injuries (OASIS) are visible third or fourth-degree perineal lacerations, reported in 2 to $12 \%$ of vaginal deliveries ${ }^{6,7}$. Occult anal sphincter lesions, which are not noticed at the time of delivery, can be detected by systematic endoanal ultrasonography in up to $27 \%$ of women after their first vaginal delivery ${ }^{8}$. Anal sphincter lesions may result in anal incontinence in $9 \%$ of women ${ }^{7,8}$. Instrumental delivery is the most important risk factor for anal incontinence, with anal sphincter lesions reported in up to $63 \%$ to $82 \%$ of forceps deliveries ${ }^{8}$ and anal incontinence in $23 \%^{8}$. Post-delivery anal incontinence decreases over time, but it contributes to anal incontinence in the long term ${ }^{9}$.

In case of anal sphincter lesions at the first delivery, cesarean section (CS) is often discussed for subsequent deliveries, with the purpose of protecting anal function. However, recommendations differ between coun- 
tries and centers. 10 1112. Current ACOG guidelines state that women with a history of OASIS who are asymptomatic and without any evidence of sphincter compromise may be allowed to have a vaginal delivery, however it is reasonable to perform a cesarean delivery based on patient request ${ }^{13}$. To date there is no high-level evidence from a randomized trial to inform the decision ${ }^{13}$. The potential benefit needs to be proven, since CS is a major surgical procedure with risks for the mother and infant ${ }^{14}$, including maternal morbidities and mortality at the time of the surgery and during subsequent pregnancies ${ }^{15}$. In recent retrospective cohort studies comparing CS versus repeat VD in women with a history of anal sphincter lesions, no significant difference was found in the incidence of anal incontinence ${ }^{9,16}$. However, the limitations were the potential indication bias inherent to observational studies and the retrospective design. The potential benefit of prophylactic CS on urinary incontinence, quality of life and sexual functions also must be addressed, as they deeply impact quality of life ${ }^{2,17}$. Our main purpose was to evaluate whether anal incontinence could be prevented by planned CS for the second delivery, in women with asymptomatic anal sphincter disruption after the first delivery.

\section{Methods}

\section{Study design}

The multicenter, prospective, randomized, open EPIC (Etude de Prévention de l'Incontinence par Césarienne) trial compared planned CS to planned VD for the second delivery in women with a history of a traumatic first delivery with anal sphincter lesions on endosonography and no self-reported anal incontinence at baseline.

Women were recruited in 6 maternity units in the Paris area (5 academic centers and 1 general hospital), between 01/04/2008 and 29/12/2014, with their written, informed consent for each of the 2 steps of the study. The study was approved by an ethics committee (Comité de Protection des Personnes Ile de France V, Paris, France).

\section{Participants}

Women having a history of a traumatic first delivery were first assessed for eligibility for anal ultrasonographic examination by the obstetrician at clinic visits in the third trimester of their second pregnancy. Women were eligible if they had a first vaginal instrumental delivery with forceps (vacuum extractions were not considered) and/or with a diagnosis of a third-degree perineal tear, had no self-reported anal incontinence at inclusion, were 18 years old or over, and signed informed consent to participate. The main exclusion criteria were a history of anal surgery, a fourth-degree perineal tear at the first delivery, self-reported AI, defined as involuntary leakage of gas or stools and any other indication for planned CS for non-proctologic reasons. After inclusion, women had a proctological evaluation including the Vaizey score ${ }^{18}$ and anal endosonography with the same expert operator (LA). The Vaizey score was chosen for its sensitivity by accounting for 24 components of AI, including the loss of flatus with or without the loss of liquid and solid stool, pad use, stool urgency, medication use and quality of life. Endosonography was performed with an ultrasound scanner with a rotating rectal probe, a multifrequency of 7-10 MHz, and a hard sonolucent plastic cone (Bruel and Kjaer,Naemm, Denmark). Three anal canal levels (upper,middle, and lower) were studied and recorded (videorecorder, Sony, Tokyo, Japan). External anal sphincter lesions, as well as any internal sphincter lesions, were characterized as defined by Law et al. ${ }^{19}$, according to defect angle and defined as severe if more than $90^{\circ}$. In case of anal sphincter lesions at endosonography, the patient was eligible for the randomized part of the trial.

\section{Trial procedures}

Women with external anal sphincter lesions at ultrasound were offered to participate in the randomized trial, and if they consented were assigned (1:1 ratio) to planned CS at 39 weeks' gestation or vaginal delivery. Concealment was obtained by use of a computer-generated randomization scheme, in various-sized blocks, stratified by center, and by use of separate serialized sealed and opaque envelopes prepared by the sponsor. Investigator or participant blinding to group assignment was not feasible, but investigators were unaware 
of aggregate outcomes during the study, since the analysis was performed only after the follow-up period was completed and the database was frozen. In the vaginal delivery group, the management of the delivery, including episiotomy, forceps or vacuum, was left to the appreciation of the clinician. In case of an emergent indication for CS unrelated to the issue of anal sphincter protection, according to the obstetrician, cross-over was allowed.

\section{Outcomes}

Standard obstetrical and perinatal outcomes were recorded at delivery and the post-partum period. Study visits were planned with the proctologist and the obstetrician at 6-8 weeks post-partum and 6 months (up to 24 months). The 6-8 weeks and 6 months follow-up visit included the Vaizey, Wexner, FSFI, physical and mental SF12 and MUH scores. In addition, the 6 -months visit included an anal ultrasound examination. The primary outcome was anal incontinence at 6 months after delivery (M6), as measured by the Vaizey score 18. Secondary endpoints were anal incontinence (Vaizey score) at 6 to 8 weeks after delivery (W6-8); postpartum transient anal incontinence (at least 1 stool and/or at least 2 gas leakages after delivery, which has disappeared at W6-8), maternal morbidities (hemorrhage, uterine rupture, placenta accreta, hematomas, cervico-vaginal lacerations, hemoperiteum, organ wounds, anesthesic complications, infections, deep vein thrombosis), fetal/neonatal morbidities (respiratory distress, infection, acidosis, trauma, neonatal intensive care), urinary continence meaured with the Measurement of Urinary Handicap (MUH) score, quality of life with the 12-Item Short-Form Health Survey (SF12) score ${ }^{20}$, women's sexuality with the Female Sexual Function Index (FSFI) ${ }^{21}$ and worsening of external sphincter lesions (defined as increase of angulation from baseline of more than 10 degrees) measured 6 months after delivery.

\section{Statistical analysis}

Assuming a mean (SD) Vaizey score at M6 of 5 (6) in the control group ${ }^{8,18}, 86$ women/group would provide $90 \%$ power at a 2 -sided $\alpha$-level of 0.05 to detect a clinically meaningful difference of mean Vaizey score of 3 between groups. The target for enrollment was increased to account for potential loss to follow-up..

Baseline characteristics are reported by trial group (CS and VD) as numbers (\%) for categorical variables and means $( \pm$ standard deviations, $\mathrm{SD})$ or medians [interquartile range, IQR] for continuous variables, as appropriate.

All analyses were performed according to the intention-to-treat (ITT) principle. Missing data were handled using multiple imputations ( 5 datasets) on principal and secondary endpoints except maternal and neonatal outcomes. The Vaizey score at M6 post-partum was compared between CS and VD groups using a permutation test, as this variable was not normally distributed and showed a floor effect. A post-hoc subgroup analysis of the primary outcome was conducted in the 27 women with Vaizey scores [?] 5 (a cut-off usually defining anal incontinence ${ }^{22}$ ) at the prenatal visit, after testing positive for interaction with trial arm. Secondary outcomes were compared between VD and CS groups using Chi-square or Fisher exact test, Student, Wilcoxon or permutation test as appropriate.

All statistical analyses were performed using SAS V.9.4 (SAS Institute Inc., Cary, North Carolina, USA).

\section{Results}

A total of 549 women were included, of whom 434 had anal endosonography, which showed that 264 (60.8\%) had anal sphincter lesions. Of these, $222(84.1 \%)$ accepted to be randomized, 112 were assigned to planned VD and 110 to planned CS (Figure 1, Flowchart). Among the 222 randomized women, 20 (9.0\%) had third-degree perineal tears during spontaneous VD at the first delivery and $202(91.0 \%)$ had forceps delivery including $140(71.1 \%)$ without perineal tears and $29(14.7 \%)$ with third-degree perineal lacerations (table 1). Although according to the eligibility criteria, none of the women self-reported any anal incontinence symptom at inclusion, the Vaizey score was calculated during the data analysis as being [?]5 in 27 women before the second delivery, corresponding to the definition of symptomatic anal incontinence. The flow chart is reported in figure 1. Women who did not complete the M6 visit did not differ from those who completed this visit except for age (see supplementary appendix). 


\section{Trial procedures}

For the second delivery, 17 (15.6\%) women in the VD arm had CS for obstetrical indications, whereas 18 $(16.5 \%)$ women in the CS arm delivered vaginally (table 2). In the VD arm, 5 women had (5.5\%) forceps delivery and 1 (1.9\%) 3d degree lacerations during spontaneous VD. Description of the second deliveries is reported in table 2 .

\section{Outcomes}

Primary and secondary outcomes are reported in Table 3. At W6-8 after delivery, anal incontinence was not statistically different between trial arms, nor was post-partum transient anal incontinence $(11.7 \%$ in the CS arm vs $25.0 \%$ in the VD arm (absolute risk difference [95\% CI]: -13.3 [-25.1 to 0.0]).

At M6, the median [IQR] Vaizey score for anal incontinence was $1 / 24$ [0-4] in the CS arm vs 1/24 [0-3] in the VD arm $(\mathrm{p}=0.34)$ (figure 2$)$. This primary outcome was actually measured at a median [IQR] time of 8.0 [6.8 - 11.2] months post-partum. When comparing Vaizey scores at inclusion and at the M6 visit, the results did not differ between the CS and VD groups (median (IQR) differences 0.0 [-1.5-2.0] and 0.0 $[0.0-1.0]$, respectively, $\mathrm{p}=0.9825)$. The effect of trial arm on Vaizey score at M6 differed between women with Vaizey score at inclusion $<5$ and women with Vaizey score at inclusion [?]5 (significant interaction, $\mathrm{p}=0.008$ ). Post-hoc subgroup analyses showed that in the subgroup of 27 women with a Vaizey score before delivery [?]5, Vaizey score at M6 were significantly lower in the CS than in the VD arm (median 3 IQR [0-7] vs $6[3.5-8.5], \mathrm{p}=0.026)$.

At M6, there was no statistically significant difference between groups for urinary incontinence (MUH score), sexual function (FSFI) and physical and mental quality of life assessed with SF12.

Regarding maternal morbidity, 4 (4.9\%) patients had at least one minor complication in the VD arm and $8(8.8 \%)$ in the CS arm, including $3(3.3 \%)$ anesthetic complications (headaches) in the CS arm and none in the VD arm. For neonatal outcomes, $5(6.1 \%)$ had at least one complication in the VD arm including 4 transfers to neonatal care units ( 2 for respiratory distress and 2 for infection) versus none in the CS arm.

Among the 222 randomized women, 125 (56.3\%) had post-partum endosonography at the M6 visit, 61 $(54.5 \%)$ in the VD arm and $64(58.2 \%)$ in the CS arm. Baseline characteristics of these women did not differ from those without endosonography (see supplementary appendix). External sphincter lesions deteriorated more frequently in the VD arm than in the CS arm (11 (22.4\%) women vs 1 (2.2\%), absolute risk difference -20.2 [95\% CI: -31.7 to -7.6$]$ ), but no additional internal sphincter lesions were observed.

\section{Discussion}

Main Findings : In this randomized trial of women with asymptomatic anal sphincter lesions resulting from a first delivery, planned cesarean section for the second delivery was not protective against anal incontinence at 6 months post-partum. In addition, we failed to show any benefit of cesarean section in this population on quantitative evaluations of urinary incontinence, sexual functions or quality of life. These results should be useful for clinicians and women, avoiding numerous unnecessary cesarean sections ${ }^{12}$.

Results vis-a-vis other studies : Our findings are consistent with those from recent observational studies, including longer follow-up ${ }^{16,23}$. In a recent observational cohort study, CS for women with anal sphincter disruption at the first delivery was associated with no benefit on anal incontinence 5 years after the second delivery ${ }^{16}$. However, most women who sustained obstetric injuries develop anal incontinence later, after their 50s. Nygaard et al ${ }^{24}$ found that anal sphincter disruption following an index delivery was a risk factor for flatus incontinence 30 years later. Some large population-based cohort studies failed to show any difference in the incidence of flatus incontinence in women above 50 years old, according to whether they delivered vaginally or by $\mathrm{CS}^{17}$, but a recent population-based study from Sweden found that the risk of anal incontinence was lower after CS than after VD ${ }^{25}$. In this study, AI also was higher among women who delivered by CS compared with nulliparous and higher among nulliparous compared with men. In another study, an association has been found between ultrasound diagnosis of anal sphincter lesions and long-term 
fecal incontinence after a first delivery ${ }^{26}$. Because anal incontinence is multifactorial, including neurological and gastro-intestinal as well as mechanical causes, this symptom can occur without sphincter lesions and vice versa. Anal sphincter lesions are observed by ultrasound in less than half of women with postpartum anal incontinence ${ }^{8}$. In an unselected primiparous population, anal sphincter disruption was detected by ultrasound screening after delivery in $27 \%$ of women, most of whom had no symptoms ${ }^{27}$. Thus, although CS can be protective from anal sphincter lesions ${ }^{8,9}$, ultrasound evidence is one of many factors associated with anal continence. Besides, it has been shown that the severity of the anal sphincter lesion is an important risk factor for subsequent anal incontinence, particularly the depth of the disruption of both the external and internal sphincter ${ }^{28}$. In our trial, we did not observe a protective effect of CS in the subgroup with severe anal sphincter ruptures (defined as $>90 \mathrm{deg}$ )(data not shown). In another study, only 4th-degree tears were associated with an increased risk of anal incontinence at 10 months postpartum ${ }^{29}$, but this was an exclusion criterion in our trial.

One important difference between our study and most retrospective studies was the inclusion of women whose first delivery was by forceps, even in the absence of a diagnosis of a third-degree perineal laceration.

Some observational studies have shown that a subsequent vaginal delivery following an obstetrical anal sphincter injury may result in additional or recurrent lesions ${ }^{30}$, which may be apparent or occult, however without any significant change in the continence score according to the mode of delivery. In our trial, the incidence of repeated clinically apparent OASIS was low, since only one woman had a repeated $3^{\text {rd }}$ degree tear.

Endosonographic aggravation of external sphincter lesions occurred significantly more often in the VD group than the CS group. These findings may indicate that CS avoids some occult sphincter disruptions, but on the other hand they signify that ultrasound evidence of anal sphincter lesions is not predictive of symptoms of anal incontinence.

Clinical implications: Our results do not support a policy of systematic prophylactic CS in women with asymptomatic ultrasound anal sphincter lesions resulting from a first delivery. However, we cannot exclude a protective effect of prophylactic CS for women with symptomatic anal sphincter lesions. In a subgroup analysis, we did find a significant benefit of CS among women with mild clinical anal incontinence detected before the second delivery at the proctological visit. Since it is a post-hoc analysis, it must be interpreted with caution. Our findings underline the importance of correct diagnosis of anal incontinence.

Because of the taboos surrounding anal incontinence, it is difficult to reveal without meticulous questioning. In our study, 27 women self-reported no anal incontinence at inclusion, but had a Vaizey score [?] 5 at the visit with a proctologist. Comparatively to endosonography, clinical-based diagnosis of anal incontinence is less expensive, more accessible and appears to be more predictive of functional outcome, as has been previously suggested in retrospective studies ${ }^{16,23}$. Thus, our findings do not support performing anal endosonography for women with an overt OASI or forceps instrumentation for their first delivery in order to decide on the mode of delivery.

Research Implications : Further studies are needed to determine whether CS may be useful in the long term, among women with mildly symptomatic anal lesions, and if so whether women with third- or fourthdegree perineal tears and/or forceps at their first delivery can benefit from a proctological examination in order to make a decision regarding their subsequent deliveries. ${ }^{8}$

Strengths/Limitations: This trial has several strengths. To our knowledge, it is the first randomized controlled trial addressing this issue. Also, anal incontinence was assessed with a standardized, validated and widely used score, the Vaizey score, and sphincter lesions were defined by endosonography. Third, the external validity was supported by the diversity of trial settings, including teaching hospitals and general hospitals in diverse populations from neighborhoods ranging from poor to affluent, with no center effect.

This trial also has limits. It was necessarily unblinded, and the main outcomes were patient-reported, thus we cannot exclude patient reporting bias. However, all investigators were unaware of aggregate outcomes 
during the study. Also, crossovers were observed (cesareans in the vaginal delivery group and vice versa), as expected in this pragmatic trial comparing strategies (planned CS or planned VD). Lastly, one fifth of the randomized women did not complete the 6 months post-partum follow-up, which could lead to attrition bias; however their characteristics did not differ between the two study groups, and multiple imputations were performed for missing variables and comparisons were based on all the patients randomized.

\section{Conclusion}

In this randomized trial of women with anal sphincter lesions resulting from their first delivery, anal incontinence was rare 6 months after second delivery and planned CS was not associated with a decrease of this risk. These findings are not in favor of recommending CS for subsequent deliveries in case of asymptomatic obstetrical anal sphincter lesions. Acknowledgmen ts

We thank Coralie Gernez, Amandine Fauquembergue, Aline Dechanet and Marion Schneider from the Unite de Recherche Clinique of Hopital Bichat-Claude-Bernard for their efforts in project management, enrollment, data collection, monitoring and data management of the trial, all the staff members of the participating maternities, the women who participated.

We also thank Drs Anabela RODRIGUES, Amelie BENBARA and Guillaume GIRARD for strong motivation of womens inclusions.

\section{All the authors report no conflict of interest.}

\section{Contribution to authorship}

LA, FT and ABM contributed to the design of this study. LA, ALT, CCC, OP included most of the patients. LA, LM, CR and FT conducted the analyses and LA, LM, ABM, ALT, CCC, OP, CR and FT contributed to the interpretation of data. LA, LM and FT drafted the manuscript and all the authors critically revised the manuscript and approved the version to published.

Trial Registration : EPIC trial. ClinicalTrials.gov number, NCT00632567

This study (Ndeg ID-RCB 2006-A00518-43) was approved by the Comite de Protection des Personnes (Ethical Human Subjects Protection Review) Paris-Ile-de-France V of Saint Antoine Hospital PARIS 12 on the 02 October 2007 (ndeg07709) and French Health Authority on 22 October 2007 (Ref: DGS2007-0188).

\section{References}

1. Mous M, Muller SA, de Leeuw JW. Long-term effects of anal sphincter rupture during vaginal delivery: faecal incontinence and sexual complaints. BJOG : an international journal of obstetrics and gynaecology 2008; 115 (2): 234-8.

2. Otero M, Boulvain M, Bianchi-Demicheli F, et al. Women's health 18 years after rupture of the anal sphincter during childbirth: II. Urinary incontinence, sexual function, and physical and mental health. $A m$ J Obstet Gynecol 2006; 194 (5): 1260-5.

3. Desseauve D, Proust S, Carlier-Guerin C, Rutten C, Pierre F, Fritel X. Evaluation of long-term pelvic floor symptoms after an obstetric anal sphincter injury (OASI) at least one year after delivery: A retrospective cohort study of 159 cases. Gynecol Obstet Fertil2016; 44 (7-8): 385-90.

4. Sharma A, Yuan L, Marshall RJ, Merrie AE, Bissett IP. Systematic review of the prevalence of faecal incontinence. Br J Surg 2016;103 (12): 1589-97.

5. Menees SB, Almario CV, Spiegel BMR, Chey WD. Prevalence of and Factors Associated With Fecal Incontinence: Results From a Population-Based Survey. Gastroenterology 2018; 154 (6): 1672-81 e3.

6. Gurol-Urganci I, Cromwell DA, Edozien LC, et al. Third- and fourth-degree perineal tears among primiparous women in England between 2000 and 2012: time trends and risk factors. BJOG : an international journal of obstetrics and gynaecology 2013;120 (12): 1516-25. 
7. Oberwalder M, Connor J, Wexner SD. Meta-analysis to determine the incidence of obstetric anal sphincter damage. Br J Surg 2003;90 (11): 1333-7.

8. Abramowitz L, Sobhani I, Ganansia R, et al. Are sphincter defects the cause of anal incontinence after vaginal delivery? Results of a prospective study. Dis Colon Rectum 2000; 43 (5): 590-6; discussion 6-8.

9. Jango H, Langhoff-Roos J, Rosthoj S, Saske A. Long-term anal incontinence after obstetric anal sphincter injury-does grade of tear matter? Am J Obstet Gynecol 2018; 218 (2): 232 e1- e10.

10. McKenna DS, Ester JB, Fischer JR. Elective cesarean delivery for women with a previous anal sphincter rupture. Am J Obstet Gynecol2003; 189 (5): 1251-6.

11. Farrar D, Tuffnell DJ, Ramage C. Interventions for women in subsequent pregnancies following obstetric anal sphincter injury to reduce the risk of recurrent injury and associated harms. The Cochrane database of systematic reviews 2014; (11): CD010374.

12. Long E, Jha S. Factors that influence patient preference for mode of delivery following an obstetric anal sphincter injury. Eur J Obstet Gynecol Reprod Biol 2018; 221 : 28-33.

13. ACOG Practice Bulletin No. 198: Prevention and Management of Obstetric Lacerations at Vaginal Delivery. Obstet Gynecol 2018;132 (3): e87-e102.

14. Lumbiganon P, Laopaiboon M, Gulmezoglu AM, et al. Method of delivery and pregnancy outcomes in Asia: the WHO global survey on maternal and perinatal health 2007-08. Lancet 2010; 375 (9713): 490-9.

15. Ducarme G, Pizzoferrato AC, de Tayrac R, et al. Perineal prevention and protection in obstetrics: CNGOF clinical practice guidelines.J Gynecol Obstet Hum Reprod 2019; 48 (7): 455-60.

16. Jango H, Langhoff-Roos J, Rosthoj S, Sakse A. Mode of delivery after obstetric anal sphincter injury and the risk of long-term anal incontinence. Am J Obstet Gynecol 2016; 214 (6): 733 e1- e13.

17. Fritel X, Ringa V, Varnoux N, Zins M, Breart G. Mode of delivery and fecal incontinence at midlife: a study of 2,640 women in the Gazel cohort. Obstet Gynecol 2007; 110 (1): 31-8.

18. Vaizey CJ, Carapeti E, Cahill JA, Kamm MA. Prospective comparison of faecal incontinence grading systems. Gut 1999; 44 (1): 77-80.

19. Law PJ, Bartram CI. Anal endosonography: technique and normal anatomy. Gastrointest Radiol 1989; 14 (4): 349-53.

20. Ware J, Jr., Kosinski M, Keller SD. A 12-Item Short-Form Health Survey: construction of scales and preliminary tests of reliability and validity. Med Care 1996; 34 (3): 220-33.

21. Rosen R, Brown C, Heiman J, et al. The Female Sexual Function Index (FSFI): a multidimensional self-report instrument for the assessment of female sexual function. J Sex Marital Ther 2000; 26 (2): 191-208.

22. Perry S, Shaw C, McGrother C, et al. Prevalence of faecal incontinence in adults aged 40 years or more living in the community. Gut 2002; 50 (4): 480-4.

23. Fradet-Menard C, Deparis J, Gachon B, et al. Obstetrical anal sphincter injuries and symptoms after subsequent deliveries: A 60 patient study. Eur J Obstet Gynecol Reprod Biol 2018;226 : 40-6.

24. Nygaard IE, Rao SS, Dawson JD. Anal incontinence after anal sphincter disruption: a 30-year retrospective cohort study. Obstet Gynecol 1997; 89 (6): 896-901.

25. Larsson C, Hedberg CL, Lundgren E, Soderstrom L, TunOn K, Nordin P. Anal incontinence after caesarean and vaginal delivery in Sweden: a national population-based study. Lancet 2019;393 (10177): $1233-9$.

26. Guzman Rojas RA, Salvesen KA, Volloyhaug I. Anal sphincter defects and fecal incontinence 15-24 years after first delivery: a cross-sectional study. Ultrasound Obstet Gynecol 2018;51 (5): 677-83. 
27. Faltin DL, Boulvain M, Irion O, Bretones S, Stan C, Weil A. Diagnosis of anal sphincter tears by postpartum endosonography to predict fecal incontinence. Obstet Gynecol 2000; 95 (5): 643-7.

28. Roos AM, Thakar R, Sultan AH. Outcome of primary repair of obstetric anal sphincter injuries (OASIS): does the grade of tear matter? Ultrasound Obstet Gynecol 2010; 36 (3): 368-74.

29. Laine K, Skjeldestad FE, Sanda B, Horne H, Spydslaug A, Staff AC. Prevalence and risk factors for anal incontinence after obstetric anal sphincter rupture. Acta Obstet Gynecol Scand 2011;90 (4): 319-24.

30. Fitzpatrick M, Cassidy M, Barassaud ML, et al. Does anal sphincter injury preclude subsequent vaginal delivery? Eur J Obstet Gynecol Reprod Biol 2016; 198 : 30-4.

Figure: Enrollment, Randomization, and Follow-up of the Study Participants

Table 1. Baseline characteristics of women randomized*

Lost to follow-up

Presentation Cephalic, no. (\%) Breech, no. (\%) Transverse, no. (\%)

Actual mode of delivery Vaginal, no. (\%) Cesarean, no. (\%)

In case of vaginal delivery Vacuum, no. (\%) Forceps, no. (\%) Anterior presentation, no. (\%) Missing data Posterior present

Treatments after 2nd delivery Iron supplements, no. (\%) Laxatives, no. (\%)

*There was no significant differences $(\mathrm{p}<0.05)$ between the trial arms.

Table 2. Description of the second deliveries*

Lost to follow-up

Presentation Cephalic, no. (\%) Breech, no. (\%) Transverse, no. (\%)

Actual mode of delivery Vaginal, no. (\%) Cesarean, no. (\%)

In case of vaginal delivery Vacuum, no. (\%) Forceps, no. (\%) Anterior presentation, no. (\%) Missing data Posterior present

Treatments after 2nd delivery Iron supplements, no. (\%) Laxatives, no. (\%)

Data are mean $\pm \mathrm{SD}$ or median [inter-quartile range] or $\mathrm{n}(\%)$

*There was no significant differences between the trial arms $(\mathrm{p}<0.05)$, except for the occurrence of perineal laceration among women having undergone vaginal delivery (absolute difference risk [CI 95\%]: -27.1 [-49.7 to -1.4]). Table 3 : Outcomes

\begin{tabular}{|c|c|c|c|c|}
\hline Endpoint & $\begin{array}{l}\text { Vaginal delivery } \\
\operatorname{arm}(\mathrm{N}=112)\end{array}$ & $\begin{array}{l}\text { Cesarean section } \\
\operatorname{arm}(\mathrm{N}=110)\end{array}$ & $\begin{array}{l}\text { Median or mean } \\
\text { difference or } \\
\text { Absolute Risk } \\
\text { Difference }(95 \% \\
\text { CI) }\end{array}$ & P Value \\
\hline $\begin{array}{l}\text { Primary } \\
\text { endpoint }\end{array}$ & & & & \\
\hline $\begin{array}{l}\text { Vaizey score at M6, } \\
\text { median }[\mathrm{IQR}] \\
\text { Secondary } \\
\text { endpoints }\end{array}$ & $1.0[0.0-3.0]$ & $1.0[0.0-4.0]$ & $0.0(0.0$ to 2.0$)$ & 0.34 \\
\hline
\end{tabular}




\begin{tabular}{|c|c|c|c|c|}
\hline Endpoint & $\begin{array}{l}\text { Vaginal delivery } \\
\operatorname{arm}(\mathrm{N}=112)\end{array}$ & $\begin{array}{l}\text { Cesarean section } \\
\operatorname{arm}(\mathrm{N}=110)\end{array}$ & $\begin{array}{l}\text { Median or mean } \\
\text { difference or } \\
\text { Absolute Risk } \\
\text { Difference }(95 \% \\
\text { CI) }\end{array}$ & P Value \\
\hline $\begin{array}{l}\text { Vaizey score at } \\
\text { W6-8, median }[\mathrm{IQR}]\end{array}$ & $0.0[0.0-3.0]$ & $0.0[0.0-3.0]$ & $0.0(-2.0$ to 1.0$)$ & \\
\hline $\begin{array}{l}\text { Post-partum } \\
\text { transient anal } \\
\text { incontinence at } \\
\text { W6-8, no. (\%) }\end{array}$ & $18(25.0)$ & $9(11.7)$ & $-13.3(-25.1$ to 0.0$)$ & \\
\hline $\begin{array}{l}\text { MUH score at } \\
\text { M6, median [IQR] }\end{array}$ & $0.0[0.0-4.0]$ & $1.0[0.0-4.0]$ & $1.0(-1.0$ to 2.0$)$ & \\
\hline $\begin{array}{l}\text { FSFI score at M6, } \\
\text { median [IQR] }\end{array}$ & $28.1[23.5-31.2]$ & $27.1[22.1-31.4]$ & $-1.0(-4.0$ to 1.9$)$ & \\
\hline $\begin{array}{l}\text { Physical SF12 score } \\
\text { at M6, mean } \pm \text { SD }\end{array}$ & $52.1(6.7)$ & $51.7(7.0)$ & $-0.4(-2.5$ to 1.6$)$ & \\
\hline $\begin{array}{l}\text { Mental SF12 } \\
\text { score at M6, } \\
\text { mean } \pm \text { SD }\end{array}$ & $46.2(9.2)$ & $46.6(9.5)$ & $0.4(-2.3$ to 3.2$)$ & \\
\hline $\begin{array}{l}\text { Maternal } \\
\text { morbidities, no. }(\%)\end{array}$ & $4(4.9)$ & $8(8.8)$ & $3.9(-2.7$ to 11.2$)$ & \\
\hline $\begin{array}{l}\text { Neonatal } \\
\text { morbidities, no. }(\%)\end{array}$ & $5(6.1)$ & $0(0.0)$ & $-6.1(-11.7$ to -1.3$)$ & \\
\hline $\begin{array}{l}\text { Worsening of } \\
\text { external sphincter } \\
\text { lesions at } \\
\text { ultrasound, no. (\%) }\end{array}$ & $11(22.4)$ & $1(2.2)$ & $-20.2(-31.7$ to -7.6$)$ & \\
\hline
\end{tabular}

All the analyses were conducted in the intent-to-treat population except maternal and neonatal morbidities (completers), and are superiority analyses. For secondary endpoints, the confidence intervals have not been adjusted and inferences drawn from the intervals may not be reproducible.

\section{Hosted file}

figure BJOG abramowitz.docx available at https://authorea.com/users/302646/articles/432742cesarean-section-in-the-second-delivery-to-prevent-anal-incontinence-after-asymptomaticobstetrical-anal-sphincter-injury-the-epic-multicenter-randomized-trial

\section{Hosted file}

CONSORT-2010-Checklist-MS-Word.doc available at https://authorea.com/users/302646/articles/ 432742-cesarean-section-in-the-second-delivery-to-prevent-anal-incontinence-afterasymptomatic-obstetrical-anal-sphincter-injury-the-epic-multicenter-randomized-trial 